\title{
Mycorrhizal Colonization, Growth and Yield of Several Promising Lines of Black Rice between Sterilized and Non-Sterilized Soil
}

\author{
Alvina Magna Anugrah ${ }^{1}$, Wayan Wangiyana ${ }^{2 *}$, I Gusti Putu Muliarta Aryana ${ }^{2}$
}

\author{
${ }^{1}$ Student of Master's Program in Management of Dryland Resources, University of Mataram (Unram) \\ ${ }^{2}$ Faculty of Agriculture, University of Mataram (Unram), Jln. Majapahit No.62, Mataram, Lombok, Indonesia, \\ *Corresponding author
}

\begin{abstract}
Sterilization of plant growing media was reported to have different effects on different crops. This research was aimed to examine the effects of autoclave sterilization of soil (sterilized vs non-sterilized) on root colonization by indigenous arbuscular mycorrhizal fung $i$ $(A M F)$, growth and yield of various genotypes of promising lines of black rice in pot culture. The pot culture experiment was conducted in a glasshouse by arranging the treatments in a factorial Completely Randomized Design with three replications. The results indicated that autoclave sterilization of soil for growing black rice significantly reduced AMF colonization, productive tiller number, average panicle length, and grain yield per clump but increased weight of 100 grains. However, there were significant interactions between sterilization and rice genotypes on plant height, AMF colonization levels, average panicle length, grain yield per clump, and weight of 100 seeds, which means different genotypes showed different responses to soil sterilization. Among seven genotypes of black rice tested, G12 showed the highest grain yield (50.93 g/pot) and G8 showed the lowest yield (37.29 g/pot) due to the highest reduction in grain yield on the sterilized soil $(46.00 \mathrm{~g} / \mathrm{pot}$ vs $28.58 \mathrm{~g} /$ pot).
\end{abstract}

Keywords- arbuscular, black rice, mycorrhiza, soil sterilization

\section{INTRODUCTION}

Ideally, growing media for use to grow crops of high economic value should be free of soilborne pathogens and should contain sufficient amount of required nutrients. Therefore, before growing those crops, the soil or growing media are usually disinfested or sterilized to avoid infection by soilborne pathogens. According to Lazarovits and Subbarao [3], Verticillium wilt, caused by the fungus Verticillium dahliae Kleb, is still the most important soilborne disease of crops worldwide. This pathogen is capable of producing microsclerotia as resting structures in the soil, which can rest in soil and plant debris for decades, and the most successful way of eradicating these structures has been the application of soil fumigation using broad spectrum fumigants [3].

Among the chemicals used for fumigation, methyl bromide was the most popular and effective fumigant for use in preplant fumigation of soil in the US agriculture, until its use was scheduled to be phased out in the US by 2001 due to the evidence that this chemical can result in depletion of the Ozone layer in the atmosphere [5]. Due to the environmental threats of methyl bromide, growers then used non-chemical techniques for sterilizing soil or growing media to eradicate or suppress soilborne pathogens to avoid soilborne diseases, especially on crops of high economic values but high risk of losses due to soilborne diseases. These involve heating of soils either using steam or solarization. The later involves heating of the soil in daily cycles for a period of several weeks [2].

Different techniques of sterilizing soils were reported to have different effects on the conditions of the soil following sterilization processes, which also affected growth and yield of crops grown on the sterilized soils. Yamamoto et al. [11] reported different effects among methyl bromide fumigation ( $\mathrm{MeBr}$ ), chloropicrin fumigation (CP), and steam sterilization (SS) on nitrogen dynamics and microbial properties of growing media in pot culture. In terms of nitrogen dynamics, all the methods of soil sterilization were reported to increase ammonium-Nitrogen over non-sterilized control, but the magnitude of increase was highest on steam sterilization followed by chloropicrin fumigation, and the least on methyl bromide fumigation. So did the severity of sterilization effects on the microbial properties of the media following sterilization decreased in the order $\mathrm{SS} \geq$ $\mathrm{CP}>\mathrm{MeBr}$ [11]. Crop growth was also reported to be different between sterilized and non-sterilized soil. Williams-Linera and Ewel [10] reported that among eight plant species, two native species grew faster on autoclave-sterilized than on non-sterilized soil but six 
species, including soybean and radish, grew better on non-sterilized than sterilized soil. In relation to inoculation of arbuscular mycorrhizal fungi (AMF), data reported by Miransari et al. [4] show that AMF inoculation on 12 time compacted non-sterilized soil tend to decrease uptake of N, P and $\mathrm{K}$ by wheat seedlings, but the same treatments tend to increase uptake of $\mathrm{N}, \mathrm{P}$ and $\mathrm{K}$ on autoclave-sterilized soil. This could mean that the indigenous AMF natively present in the non-sterilized soil were more effective than the introduced AMF isolates, but on the sterilized soil, the indigenous AMF were kill during autoclave sterilization process so that the introduced AMF isolates had no competitors in infecting roots of the wheat seedlings.

This research project was aimed to examine the effects of autoclave-sterilization of mungbean rhizosphere soil on arbuscular mycorrhiza colonization, growth and yield of various promising lines of upland black rice on pot culture in a glasshouse.

\section{MATERIALS AND METHOD}

The experiment in this study was carried out in the glasshouse of the Faculty of Agriculture, University of Mataram, Mataram, Lombok, Indonesia, by growing upland black rice in polybag pots. The growing media were taken from dry land with Entisol soil in North Lombok, which was frequently used to grow mungbean and the soil used as the growing media in this research was mungbean rhizosphere, which roots were colonized by arbuscular mycorrhizal fungi (AMF) with an average colonization level of more than $80 \%$.

\section{The treatments:}

This mungbean rhizosphere soil was used to grow 7 promising lines of upland black rice with two treatments of growing media, i.e. S0 = without sterilization (containing indigenous $\mathrm{AMF}$ ) and $\mathrm{S} 1=$ sterilized using autoclave for 2 hours at $121{ }^{\circ} \mathrm{C}$. Thus there were two treatment factors in this research, i.e. Sterilization (S) of growing media, and various genotypes of the promising lines of black rice, which are the results of hybridization $\&$ selection by rice breeding research team. Of the 15 genotypes selected, 7 promising lines with relatively high grain yield were tested in this research. Therefore, there were 14 treatment combinations, namely the genotypes G4, G7, G8, G9, G12, G13 and G15 planted on nonsterilized growing media (S0), and G4, G7, G8, G9, G12, G13 and G15 planted on the sterilized growing media (S1), and each treatment combination was made in 3 replications, so that there were 42 polybag pots.

\section{Preparation of growing media and planting:}

The mungbean rhizosphere soil from North Lombok, after being air-dried, was sieved with a $2 \mathrm{~mm}$ opening sieve and mixed evenly, and then its moisture content was measured to determine its moisture content at field capacity and air-dried condition. For the treatment of nonsterilized media (S0), 21 pieces of polybag were prepared, and then were filled with $9 \mathrm{~kg}$ of the air-dried growing media. For the treatment of sterilized growing media, 21 autoclave bags were prepared, each of which was filled with $9 \mathrm{~kg}$ of the air-dried growing media, then each was sterilized in the autoclave for 2 hours at $121{ }^{\circ} \mathrm{C}$, and after being cooled, each was used to fill a polybag pot. On the day before planting rice seeds, the growing media in the 42 polybag pots were watered with aquadest until its field capacity. Before being planted, the black rice seeds were pre-germinated, and then 4-5 germinated seeds were planted per pot, but after 7 days after seeding (DAS) thinning was done by allowing only 2 seedlings to grow per pot. When finished, soil in the pots was fertilized using Phonska (15-15-15) fertilizer at a dose of $1.2 \mathrm{~g} /$ pot (equivalent to $300 \mathrm{~kg} / \mathrm{ha}$ ), which was dibbled next to the young rice plants.

\section{Plant maintenance and harvest:}

Watering was done every 2 days when the plants were 220 days old, then every day in the morning when the plants were 21-40 days old, and after 40 DAS, watering was done 1-2 times per day depending on the soil conditions in the pots. Watering was done using tap water with the same volume per pot until the condition of field capacity at each watering. Follow-up fertilization was done using Urea $(45 \% \mathrm{~N})$ fertilizer at a dose of $0.5 \mathrm{~g} /$ pot (equivalent to $125 \mathrm{~kg} / \mathrm{ha}$ ) at the age of 30 and 50 DAS, by dibbling the fertilizer beside the base of the rice stems. Harvesting was done after the rice panicles reach harvest state, with a range of days to harvest of 95-117 days.

\section{Variable measurement and data analysis:}

Observation variables included plant height at harvest, days to harvest, degree of AMF colonization in rice roots, number of productive tillers, average panicle length at harvest, weight of dry straw, dry grain yield, and weight of 100 dry grains. To measure the degree of colonization levels, samples of rice roots were taken at anthesis using soil sampler by taking 2 soil cores per pot. The root samples after being washed were then cut into $1 \mathrm{~cm}$ pieces, then they were stained using Trypan blue followed the method used by Wangiyana [9]. Data were analyzed with analysis of variance (ANOVA) and Tukey's HSD test at 5\% level of significance, using the statistical program CoSta

$\mathrm{t}$ for Windows ver. 6.303.

\section{RESULTS AND DISCUSSION}

Based on the results of data analysis, the ANOVA results indicate that there were significant interaction effects 
between sterilization and genotypes on plant height, AMF colonization levels, average panicle length, grain yield per clump, and weight of 100 filled grains, which means that mean values of those variables on a genotype depend on whether the growing media were sterilized or not.
However, unlike the effects of genotypes, which were significant on all measurement variables except for the weight of 100 grains, the sterilization treatment only affected AMF colonization levels, and the weight of 100 filled grains (Table 1).

Table.1: Summary of ANOVA Results for All Observation Variables

\begin{tabular}{lccc}
\hline Observation variables & Steril-ization & Geno-type & Inter-action \\
\hline Plant height & $\mathrm{ns}$ & $* * *$ & $* *$ \\
Days to harvest & $\mathrm{ns}$ & $* * *$ & $\mathrm{~ns}$ \\
Straw dry weight & $\mathrm{ns}$ & $\mathrm{n}$ & $* *$ \\
AMF colonization levels & $* * *$ & $* * *$ & $\mathrm{~ns}$ \\
Productive tiller number & $* * * *$ & $*$ \\
Average panicle length & $* * *$ & $* * *$ & $* * *$ \\
Grain yield per clump & $*$ & $\mathrm{~ns}$ & $*$ \\
Weight of 100 grains & & $* *$ & \\
\hline
\end{tabular}

Remarks: $\mathrm{ns}=$ nonsignificant; ${ }^{*}, * *, * * *=$ significant at $p<0.05, p<0.01$, and $p<0.001$ respectively

Among the growth variable, only plant height showing interaction effect of both treatment factors, which means differences in plant height between genotypes depend on whether the growing media were sterilized or not, although there was no significant effect of soil sterilization on plant height. The patterns of interaction between the two factors on plant height are as in Fig. 1, in which plant height was higher on sterilized than on non-sterilized soil, but only on the genotypes $\mathrm{G} 9$ and G12. The pattern of differences in these genotypes was also similar between plant height (Fig. 1) and weight of 100 grains (Fig. 2).

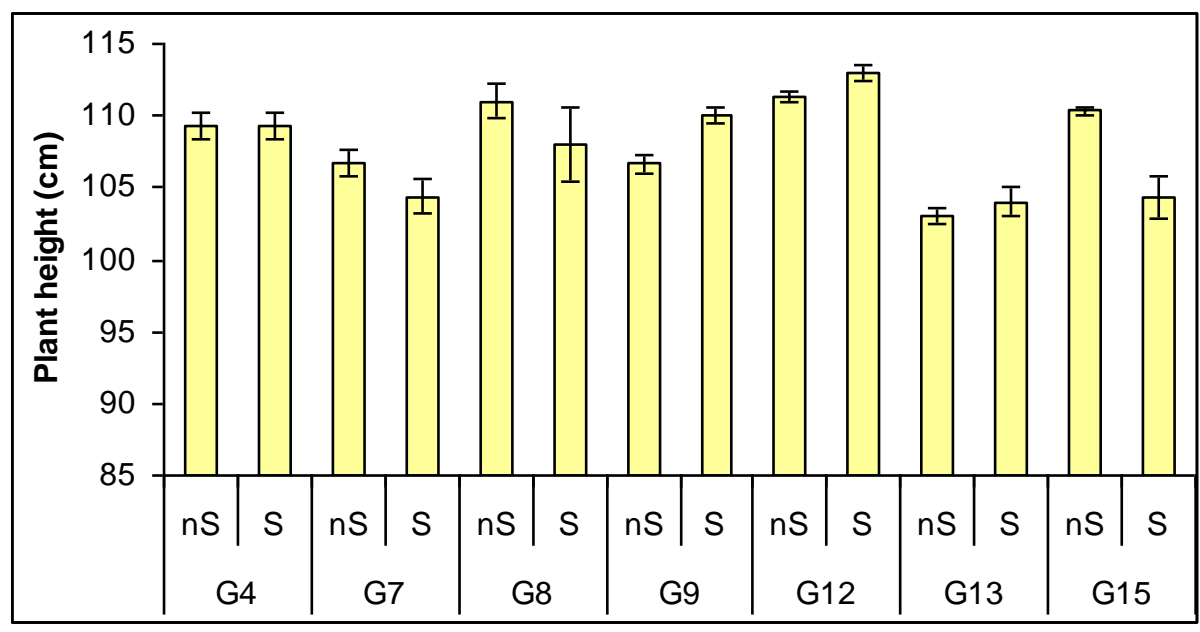

Fig.1: Average (Mean \pm SE) plant height (cm) of various promising lines of black rice between sterilized $(S)$ and nonsterilized $(n S)$ soil

In addition, average weight of 100 grains on G8 was also higher on sterilized than on non-sterilized soil (Fig. 2). On the contrary, grain yield of G8 was higher on non-sterilized than on sterilized soil (Fig. 5). This was probably due to the higher number of productive tillers per pot on the non-sterilized than sterilized soil, and this trend was similar almost on all genotypes tested (Fig. 6), although there was no interaction effect of both treatment factors on number of productive tillers per pot (Table 1). 


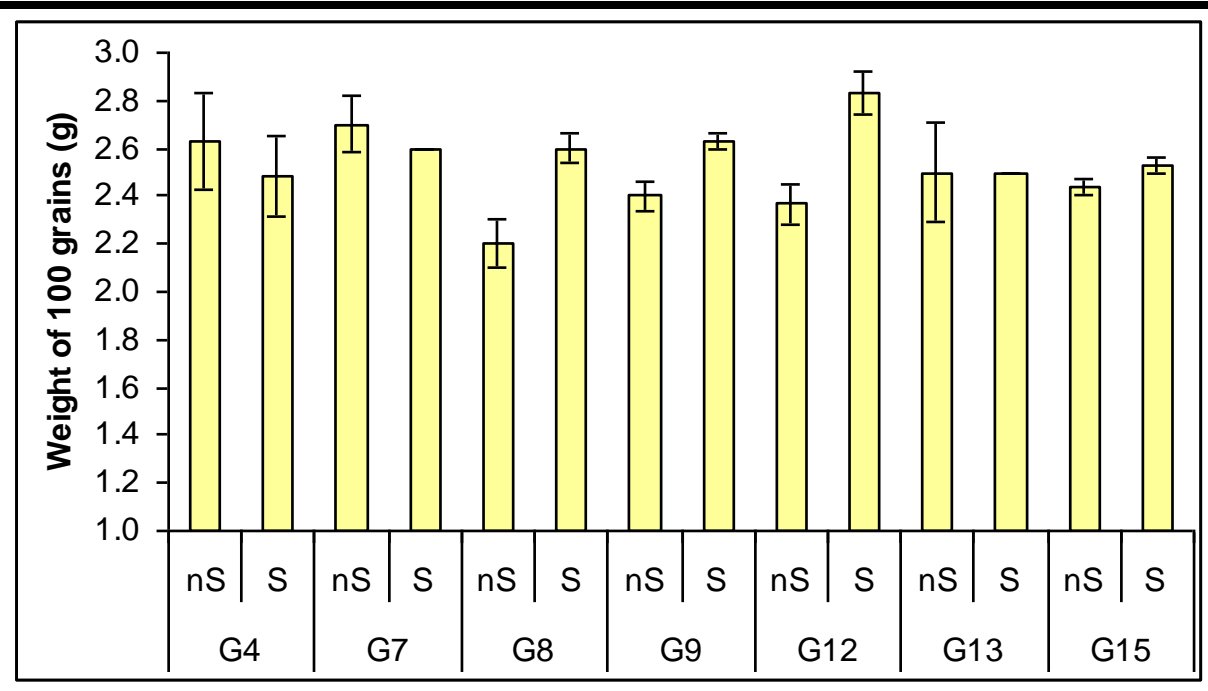

Fig.2: Average (Mean $\pm S E$ ) weight of 100 filled grains $(g)$ of various promising lines of black rice between sterilized (S) and non-sterilized $(n S)$ soil

Among the variables showing significant interaction effects of both treatment factors, there were three response variables showing both significant interaction and main effects, namely AMF colonization levels in the black rice roots, average panicle length, and grain yield per clump. For the levels of root colonization by the indigenous AMF, the significant interaction seems to be due to the highly significant differences in colonization levels between genotypes of the black rice plants grown on the non-sterilized soil, while AMF colonization on roots of those grown on the sterilized soil was not found. The patterns of interaction effects of both treatment factors are as in Fig. 3.

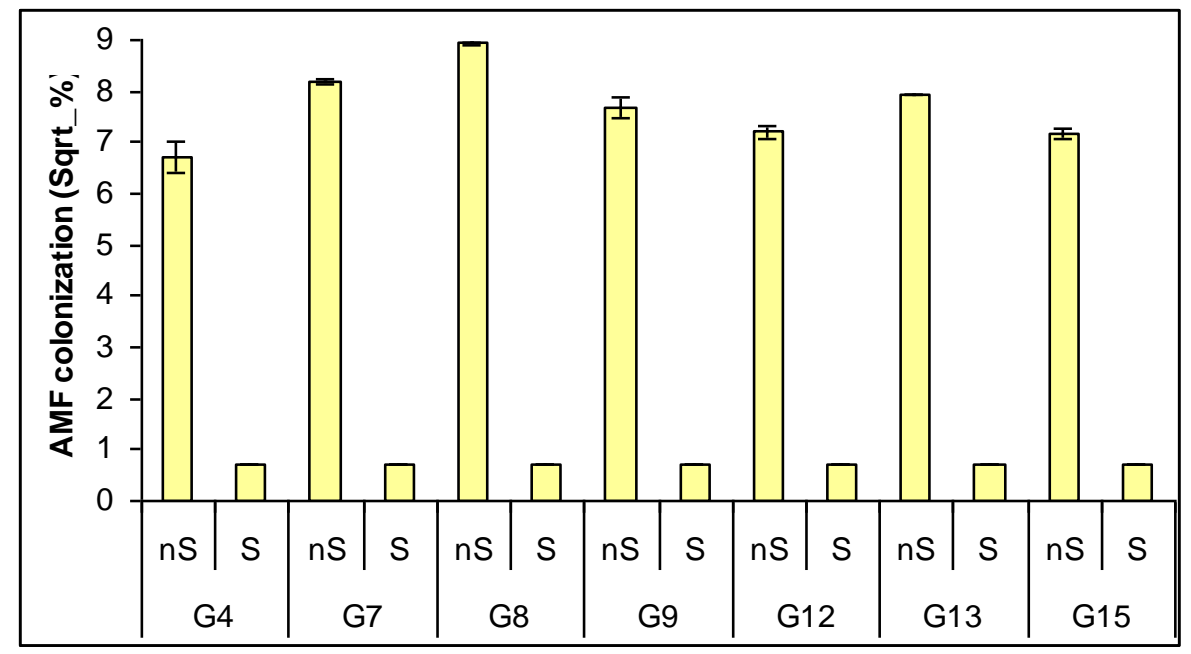

Fig.3: Average (Mean \pm SE) AMF colonization levels (data were transformed into $\sqrt{ }(x \%+0.5)$ ) on roots of various promising lines of black rice between sterilized $(S)$ and non-sterilized $(n S)$ soil

For the average panicle length, the patterns of interactions between both treatment factors are as in Fig. 4 , in which it can be seen that different genotypes responded differently, i.e. the genotypes G4, G7 and G12 showed higher panicle length on non-sterilized than on sterilized soil, while G13 showed higher panicle length on sterilized than on non-sterilized soil. 


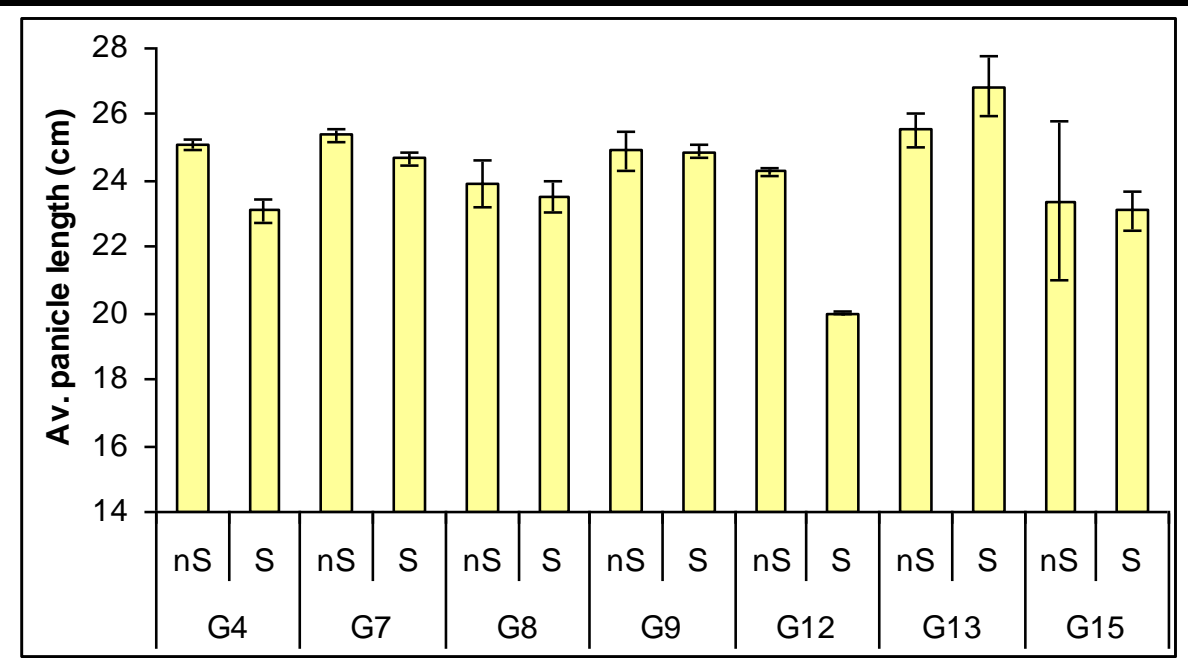

Fig.4: Average (Mean $\pm S E$ ) panicle length $(\mathrm{cm})$ of various promising lines of black rice between sterilized $(S)$ and nonsterilized $(n S)$ soil

A similar patterns of interactions also occurred on grain yield per pot, except for the genotypes G7 and G8 (Fig. 5). In relation to grain yield, the genotype G7 showed higher yield on sterilized than on non-sterilized soil, while G8 showed significantly higher grain yield on non-sterilized than on sterilized soil. Thus, among the seven genotypes tested, three showing no differences in grain yield between sterilized and non-sterilized soil, three showing higher grain yield on non-sterilized soil and only one showing higher grain yield on sterilized soil, i.e. G7 (Fig. 5).

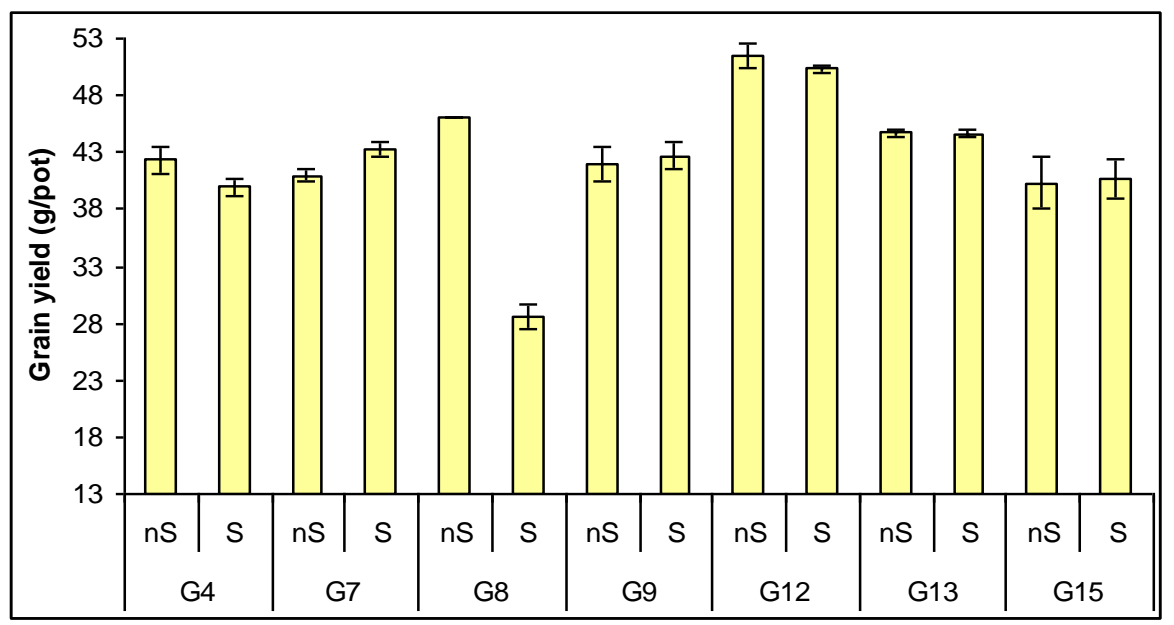

Fig.5: Average (Mean $\pm S E)$ grain yield (g/pot) of various promising lines of black rice between sterilized $(S)$ and nonsterilized $(n S)$ soil

In the case of grain yield of G7, which was higher on the sterilized than on the non-sterilized soil (Fig. 5), it is clearly unrelated to productive tiller number (Fig. 6), average panicle length (Fig. 4), AMF colonization levels (Fig. 3), or weight of 100 grains (Fig. 2), because they were higher on non-sterilized than on the sterilized soil. However, dry straw weight on the genotype G7 was higher on sterilized than on non-sterilized soil (Fig. 7), although there was no significant interaction affect on dry straw weight (Table 1). The genotype G7 was harvested on the same day both for the plants on the sterilized and on non-sterilized soil, so that the duration of their seed filling period was the same between the two growing media. According to Wang et al. [8], carbon reserve in the stem and leaves of rice plants can be remobilized to developing seeds during the grain filling period, to increase grain yield. Since the grain filling duration of G7 on both growing media was the same, it was possible that the proportion of the carbon reserve remobilized to seeds was probably the same between the two growing media. Since straw dry weight of G7 was higher on sterilized than on non-sterilized soil, it could be possible that the higher grain yield of the genotype G7 growing on the sterilized than non-sterilized soil was due to the higher 
dry straw weight of $G 7$ on the sterilized than nonsterilized soil. In addition, the higher number of productive tillers of $\mathrm{G} 7$ on non-sterilized than on sterilized soil might have contributed only to a higher proportion of unfilled grains on G7 growing on the nonsterilized soil.

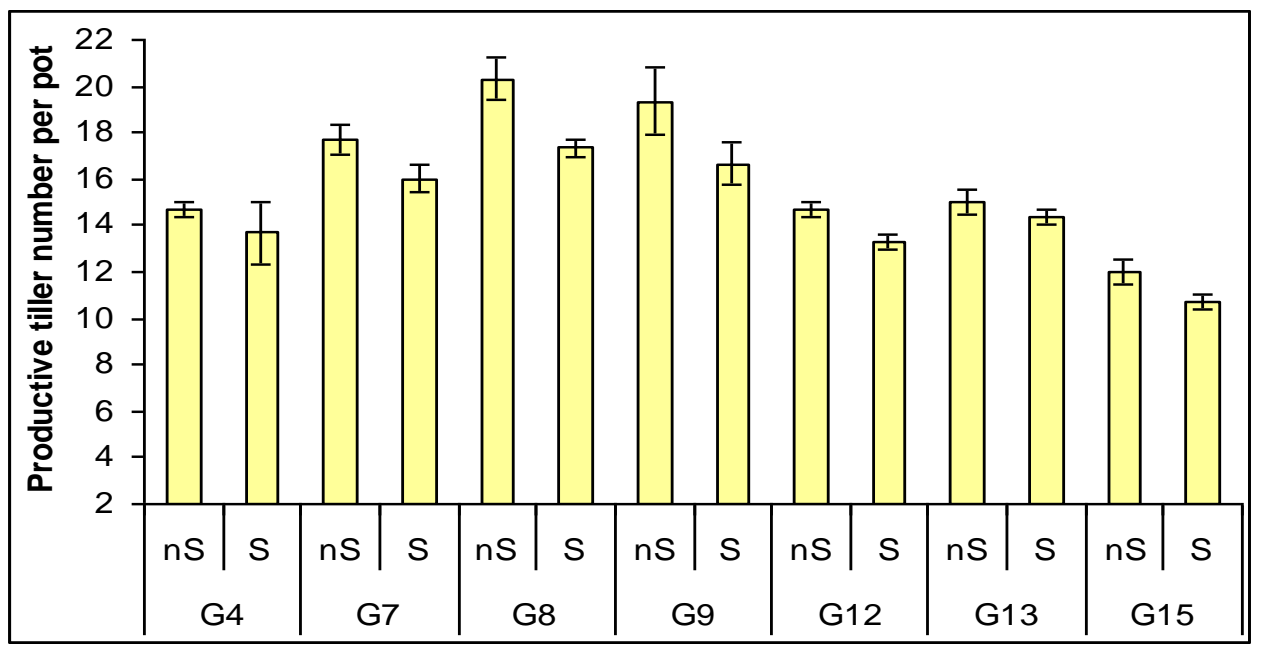

Fig.6: Average (Mean $\pm S E$ ) productive tiller number per pot of various promising lines of black rice between sterilized (S) and non-sterilized $(n S)$ soil

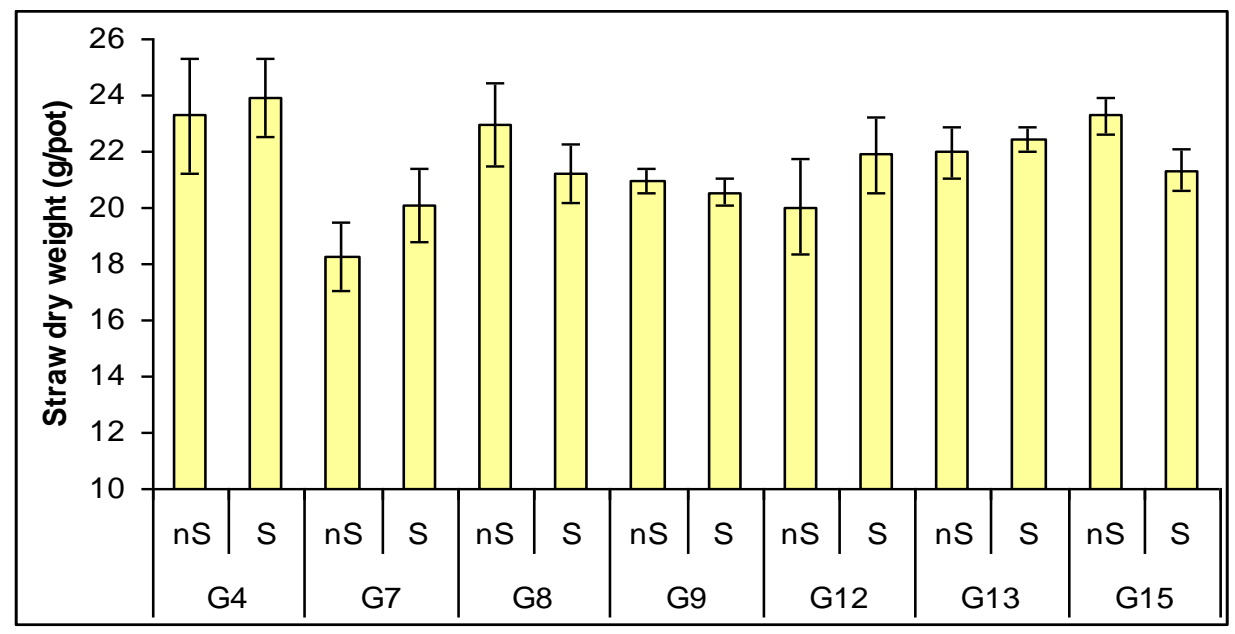

Fig.7: Average (Mean $\pm S E$ ) straw dry weight ( $g / p o t)$ of various promising lines of black rice between sterilized (S) and nonsterilized $(n S)$ soil

However, for other genotypes showing higher grain yield per pot on the non-sterilized than on sterilized soil, such as G4, G8 and G12, the most possible causes were higher productive tillers and AMF colonization in roots of black rice plants growing on the non-sterilized than on sterilized soil. The contribution of AMF colonization is well-known to help their host plants to take up more nutrients from their growing media, including $\mathrm{N}, \mathrm{P}, \mathrm{K}, \mathrm{Ca}, \mathrm{Fe}, \mathrm{Cu}, \mathrm{Na}, \mathrm{B}, \mathrm{Zn}, \mathrm{Al}, \mathrm{Mg}$ and $\mathrm{S}$ $[1,6,7]$. According to the data published by Miransari et al. [4], symbiosis was more effective with indigenous AMF than with the introduced species, and many researchers have proven that rice is a good host for AMF symbiosis [1, 6, 7]. Therefore, better nutrition due to indigenous AMF colonization coupled with higher productive tiller numbers (Fig. 6) of the black rice plants grown on the non-sterilized soil would have contributed to higher grain yield per pot (Fig. 5).

Based on the main effects on yield components of various promising lines of black rice, it can be seen from Table 2 that soil sterilization reduced productive tiller number per pot, average panicle length, and grain yield per pot, but increased weight of 100 filled grains. The lower weight of 100 filled grains on black rice plants grown on non-sterilized soil could be due to increased productive tiller number and average panicle length, which both can result in higher number of spikelet per pot, which in turn could reduce weight of 100 grains. 
Table.2: Average Grain Yield and Yield Components of Various Promising Lines of Black Rice Grown on Autoclave Sterilized and Non-sterilized Soil

\begin{tabular}{lcccc}
\hline Treatments & $\begin{array}{c}\text { Productive tiller } \\
\text { number per clump }\end{array}$ & $\begin{array}{c}\text { Average panicle } \\
\text { length }(\mathbf{c m})\end{array}$ & $\begin{array}{c}\text { Weight of 100 filled } \\
\text { grains (g) }\end{array}$ & $\begin{array}{c}\text { Dry grain yield } \\
\text { (g/pot) }\end{array}$ \\
\hline $\begin{array}{l}\text { Sterilization: } \\
\text { Non-sterilized }\end{array}$ & $16.24 \mathrm{a}$ & $24.64 \mathrm{a}$ & $2.46 \mathrm{~b}$ & $43.99 \mathrm{a}^{1)}$ \\
Sterilized & $14.57 \mathrm{~b}$ & $23.74 \mathrm{~b}$ & $2.60 \mathrm{a}$ & $41.45 \mathrm{~b}$ \\
HSD 0.05 & 0.80 & 0.85 & 0.12 & 1.24 \\
\hline Genotypes: & & & & $41.16 \mathrm{bc}$ \\
G4 & $14.17 \mathrm{c}$ & $24.09 \mathrm{abc}$ & $2.56 \mathrm{a}$ & $42.12 \mathrm{bc}$ \\
G7 & $16.83 \mathrm{ab}$ & $25.02 \mathrm{ab}$ & $2.65 \mathrm{a}$ & $37.29 \mathrm{~d}$ \\
G8 & $18.83 \mathrm{a}$ & $23.74 \mathrm{abc}$ & $2.40 \mathrm{a}$ & $42.34 \mathrm{bc}$ \\
G9 & $18.00 \mathrm{a}$ & $24.90 \mathrm{ab}$ & $2.52 \mathrm{a}$ & $50.93 \mathrm{a}$ \\
G12 & $14.00 \mathrm{c}$ & $22.14 \mathrm{c}$ & $2.60 \mathrm{a}$ & $44.69 \mathrm{~b}$ \\
G13 & $14.67 \mathrm{bc}$ & $26.20 \mathrm{a}$ & $2.50 \mathrm{a}$ & $40.50 \mathrm{~cd}$ \\
G15 & $11.33 \mathrm{~d}$ & $23.24 \mathrm{bc}$ & $2.48 \mathrm{a}$ & 3.60 \\
HSD 0.05 & 2.33 & 2.47 & 0.34 & \\
\hline
\end{tabular}

1) Mean values in each column followed by the same letters are not significantly different based on the Tukey's HSD test at $5 \%$ level of significance

\section{CONCLUSION}

Based on the overall results, it is concluded that sterilization of soil for use as growing media could reduce growth and yield of black rice probably due to eradication of AMF by the sterilization process.

\section{REFERENCES}

[1] Dhillion S.S. and Ampornpan L. 1992. The influence of inorganic nutrient fertilization on the growth, nutrient composition and vesicular-arbuscular mycorrhizal colonization of pretrans plant rice (Oryza sativa L.) plants. Biology and Fertility of Soils, 13: 8591.

[2] Katan J. and Gamliel A. 2010. Soil Solarization - 30 Years On: What Lessons Have Been Learned? In: U. Gisi et al. (eds.), Recent Developments in Management of Plant Diseases, 265-283. Springer. DOI: 10.1007/978-1-4020-8804-9_19.

[3] Lazarovits G. and Subbarao K. 2010. Challenges in Controlling Verticillium Wilt by the Use of Nonchemical Methods. In. U. Gisi et al. (eds.), Recent Developments in Management of Plant Diseases. 247264. Springer. DOI: 10.1007/978-1-4020-8804-9_18.

[4] Miransari M., Bahrami H.A., Rejali F., and Malakouti M.J. 2009. Effects of arbuscular mycorrhiza, soil sterilization, and soil compaction on wheat (Triticum aestivum L.) nutrients uptake. Soil and Tillage Research, 104: 48-55. DOI:10.1016/j.still.2008.11.006.

[5] Ristaino J.B. and Thomas W. 1997. Agriculture, MethylBromide, and the Ozone Hole: Can We Fill the Gaps? Plant Disease, 81(9): 964-977.

[6] Solaiman M.Z. and Hirata H. 1995. Effects of indigenous arbuscular mycorrhizal fungi in paddy fields on rice growth and $\mathrm{N}, \mathrm{P}, \mathrm{K}$ nutrition under different water regimes. Soil Science and Plant Nutrition, 41: 505-514.

[7] Solaiman M.Z. and Hirata H. 1996. Effectiveness of arbuscular mycorrhizal colonization at nursery-stage on growth and nutrition in wetland rice (Oryza sativa L.) after transplanting under different soil fertility and water regimes. Soil Science and Plant Nutrition, 42: 561-571.

[8] Wang G.Q., Hao S.S., Gao B., Chen M.X., Liu Y.G., Yang J.C., Ye N.H., and Zhang J.H. 2017. Regulation of Gene Expression in the Remobilization of Carbon Reserves in Rice Stems During Grain Filling. Plant and Cell Physiology, 58(8): 1391-1404. doi:10.1093/pcp/pcx072.

[9] Wangiyana W. 2004. Farming Systems Management of Arbuscular Mycorrhizal Fungifor Sustainable Crop Production in Rice-Based Cropping Systems. Ph.D. Thesis, University of Western Sydney, New South Wales, Australia. (http://library.westernsydney.edu.au/).

[10] Williams-Linera G. and Ewel J.J. 1984. Effect of autoclave sterilization of a tropical andept on seed germination and seedling growth. Plant and Soil, 82: 263-268.

[11] Yamamoto T., Ultra Jr V.U., Tanaka S., Sakurai K., Iwasaki K. 2008. Effects of methyl bromide fumigation, chloropicrin fumigation and steam sterilization on soil nitrogen dynamics and microbial properties in a pot culture experiment. Soil Science and Plant Nutrition, 54: 886-894. DOI: 10.1111/j.1747-0765.2008.00319.x 